\title{
Teachers feeling the burden of COVID-19: Impact on well-being, stress, and burnout
}

\author{
Susan E. Kotowski ${ }^{\mathrm{a}, *}$, Kermit G. Davis ${ }^{\mathrm{b}}$ and Clare L. Barratt ${ }^{\mathrm{c}}$ \\ ${ }^{\mathrm{a}}$ Department of Rehabilitation, Exercise and Nutrition Sciences, College of Allied Health Sciences, \\ University of Cincinnati, Cincinnati, $\mathrm{OH}, \mathrm{USA}$ \\ ${ }^{\mathrm{b}}$ Department of Environmental and Public Health Science, College of Medicine, University of Cincinnati, \\ Cincinnati, $\mathrm{OH}, \mathrm{USA}$ \\ ${ }^{\mathrm{c} D e p a r t m e n t ~ o f ~ P s y c h o l o g y, ~ C o l l e g e ~ o f ~ A r t s ~ a n d ~ S c i e n c e, ~ B o w l i n g ~ G r e e n ~ S t a t e ~ U n i v e r s i t y, ~ B o w l i n g ~ G r e e n, ~} \mathrm{OH}$, \\ USA
}

Received 20 July 2021

Accepted 2 December 2021

\begin{abstract}
.
BACKGROUND: Teachers have had to deal with many of the negative aspects of COVID-19 over the past year. The demands associated with the sudden requirement to teach remotely, and later having to manage hybrid (both in person and online) learning may be having adverse effects on the mental and physical health of teachers.

OBJECTIVE: To determine whether COVID-19 continued to impact teacher stress, burnout, and well-being a year into the pandemic.

METHODS: An online survey was sent out to 5300 teachers in public and private schools, and 703 completed the survey.

RESULTS: Stress and burnout continue to be high for teachers, with $72 \%$ of teachers feeling very or extremely stressed, and $57 \%$ feel very or extremely burned out. Many teachers struggled to have a satisfactory work-family balance (37\% never or almost never; $20 \%$ only has sometimes).

CONCLUSION: School systems must start to deal with the mental and physical health of teachers before a large number of them leave the profession.
\end{abstract}

Keywords: Telework, online teaching, primary school, pandemic, COVID-19

\section{Introduction}

When teachers first enter the profession, they express idealism and enthusiasm for their new adventure. They want to make a difference in students' learning and development, to impact society, and to feel that their own lives have purpose. Despite this initial enthusiasm, the teaching profession struggles

*Address for correspondence: Susan Kotowski, Department of Rehabilitation, Exercise and Nutrition Sciences, College of Allied Health Sciences, University of Cincinnati, Cincinnati, OH, USA.

E-mail: Susan.kotowski@uc.edu. with retention; turnover rates have risen continually in recent decades, and those who leave usually do so in the first five years [1-3]. These high turnover rates are most commonly attributed to the high level of occupational stress found in the profession; in fact, teaching has been reported to be one of the most stressful occupations in the world, especially for young, inexperienced teachers [4].

Stress is defined as an unpleasant emotional experience linked with specific environmental triggers and associated with feelings of anxiety, frustration, tension, and anger [5]. According to the Job Demands-Resources model, stress is a response to 
the imbalance between occupational demands on the individual and the resources he or she has to deal with those demands [6]. In other words, when demands are high and resources are low, stress and burnout are common. The occupational demands of teachers have been investigated at length for over thirty years. Not only do teachers have the responsibility of teaching students whose needs and motivation to learn vary, but they also fill an ever-changing role that is notoriously underpaid and scrutinized by the public [7]. Further, they often report little support from administration, poor relationships with colleagues, overloaded classrooms, time pressure, inadequate resources, work overload, and role conflict [5, 8-11]. Over time, these demands lead to teacher stress and burnout, which has been linked to lower self-efficacy, lower performance, lower job satisfaction, poor physical and psychological health, and turnover [12].

Although the teaching profession was already recognized as one of the most stressful, the COVID-19 pandemic brought unprecedented challenges and created new demands and stressors. By the end of March of 2020, schools in over 137 countries were closed, affecting more than 1.5 billion students around the world $[13,14]$. With the sudden closure of schools, teachers were forced to shift from traditional faceto-face teaching to online teaching with only a few days' notice. Although pre-COVID-19 evidence suggests that online teaching is not necessarily harder than conventional teaching $[15,16]$, it was the abrupt shift, often with little to no training, that induced stress and required more time to prepare [17]. Many teachers made this shift while also managing their own mental and physical health, caring for vulnerable family members, and home schooling their own children [18]. Further, teachers were uncertain about how long the closures would last, given the ever-changing communications from their local and national governments.

Emerging research indicates the COVID-19 pandemic took a severe toll on teachers. Teachers were not only worried about their own physical and mental health, but that of their students, especially highrisk students [19]. Further, studies investigating the impact of COVID-19 revealed that rates of anxiety, depression, and stress for teachers were significantly higher than pre-COVID-19 rates [20]. In all, the evidence points to COVID-19 adversely affecting the well-being and satisfaction, leading to increased burnout of teachers across the world [19-27]. As a result, the turnover rate for teachers more than doubled during the pandemic [28].
The emerging evidence clearly shows that COVID19 had an immense impact on the health and well-being of teachers. What is less clear, however, is how long these negative effects lasted. Most published studies on COVID-19's impact on teachers are based on data collected in the first few months of the pandemic [15-19, 29, 30]. There is less published work and data examining COVID-19's impact further into the pandemic. It may be that the negative effects were short-term while teachers initially struggled to adjust to the shift to online learning, but these effects tapered off as teachers eventually acclimated and found a new rhythm and schedule. Alternatively, the negative effects may be longer lasting, given that the pandemic was fraught with uncertainty about its duration and caused shifts in teaching modality as students returned to school in the fall. The current study aimed to determine whether COVID-19 continued to increase teacher stress and burnout and decrease well-being a year into the pandemic.

\section{Methods}

\subsection{Study design}

The study was a cross-sectional online survey that was administered in the spring of 2021 (for two months: April-May). The survey was designed to obtain the perceptions about pre-COVID and duringCOVID conditions for teachers in public and private schools in the Greater Cincinnati area. The survey was sent out to teachers through a link attached to an email. The protocol and survey were reviewed and approved by the University of Cincinnati's Institutional Review Board (Protocol number: 2021-0165).

\subsection{Study population}

Schools were selected from large school districts (i.e., those having multiple schools at all levels), mid-size districts, and small districts (i.e., those that had only one each elementary, middle, and high school). Public and private schools were included, and both parochial and non-parochial schools were represented among the private schools.

Once the schools were selected, email addresses for 5300 teachers were obtained from online searches of the school websites. An initial email was sent to all 5300 teachers in mid-April, and a follow-up reminder email was sent 2 weeks later. In total, 703 teachers completed the survey. See Table 1 for a complete 
Table 1

Demographics of the teachers who completed the survey

\begin{tabular}{|c|c|}
\hline \multicolumn{2}{|c|}{ Gender } \\
\hline All & 703 \\
\hline Male & 125 \\
\hline Female & 578 \\
\hline \multicolumn{2}{|c|}{ Race and ethnicity } \\
\hline Native American & 4 \\
\hline Asian & 10 \\
\hline Black & 28 \\
\hline Hawaiian & 2 \\
\hline White & 668 \\
\hline Hispanic & 10 \\
\hline \multicolumn{2}{|c|}{ Marital status } \\
\hline Divorced/separated & 45 \\
\hline Married & 546 \\
\hline Single & 106 \\
\hline Widowed & 6 \\
\hline \multicolumn{2}{|c|}{ Education } \\
\hline $\mathrm{BS}$ & 115 \\
\hline MS & 538 \\
\hline $\mathrm{PhD}$ & 11 \\
\hline $\mathrm{EdD}$ & 12 \\
\hline Special certification & 7 \\
\hline Other & 20 \\
\hline \multicolumn{2}{|c|}{ Years teaching } \\
\hline Overall & $18.5(9.2)$ \\
\hline Current school system & $11.0(8.5)$ \\
\hline \multicolumn{2}{|c|}{ Average age } \\
\hline Overall & $44.6(10.6)$ \\
\hline
\end{tabular}

description of the demographics of the subject population: age, gender, race and ethnicity, marital status, education, and teaching experience. The majority of the respondents were female ( 578 or $82 \%$ ), Caucasian or white $(668$ or $95 \%)$, married (546 or $78 \%$ ), and have a master's degree (538 or $77 \%$ ). On average, teachers had 18 years of experience with 11 years at their current school. Figure 1 provides a summary of the distribution of surveys for grade level, including the last bar that shows the number of teachers who teach multiple grades. More than half the teachers ( 385 or $55 \%$ ) taught multiple grades, which occurred mostly in the middle and high schools (94 or $24 \%$ and 257 or $67 \%$, respectively). In general, about 80 teachers per elementary grade, 100 teachers per middle school grade, and 215 teachers per high school grade completed the survey.

\subsection{Online teachers survey}

A survey was developed using REDCap (Research Electronic Data Capture) software (Cincinnati Children's Hospital Medical Center, Cincinnati, OH, USA). The software allows surveys to be customized and distributed through an electronic link that keeps all data anonymous and confidential. A 50-item survey inquired about pre-COVID-19 and during-COVID-19 conditions for teachers as well as demographics (see Table 2 for a complete list of the survey items and corresponding answer options). The

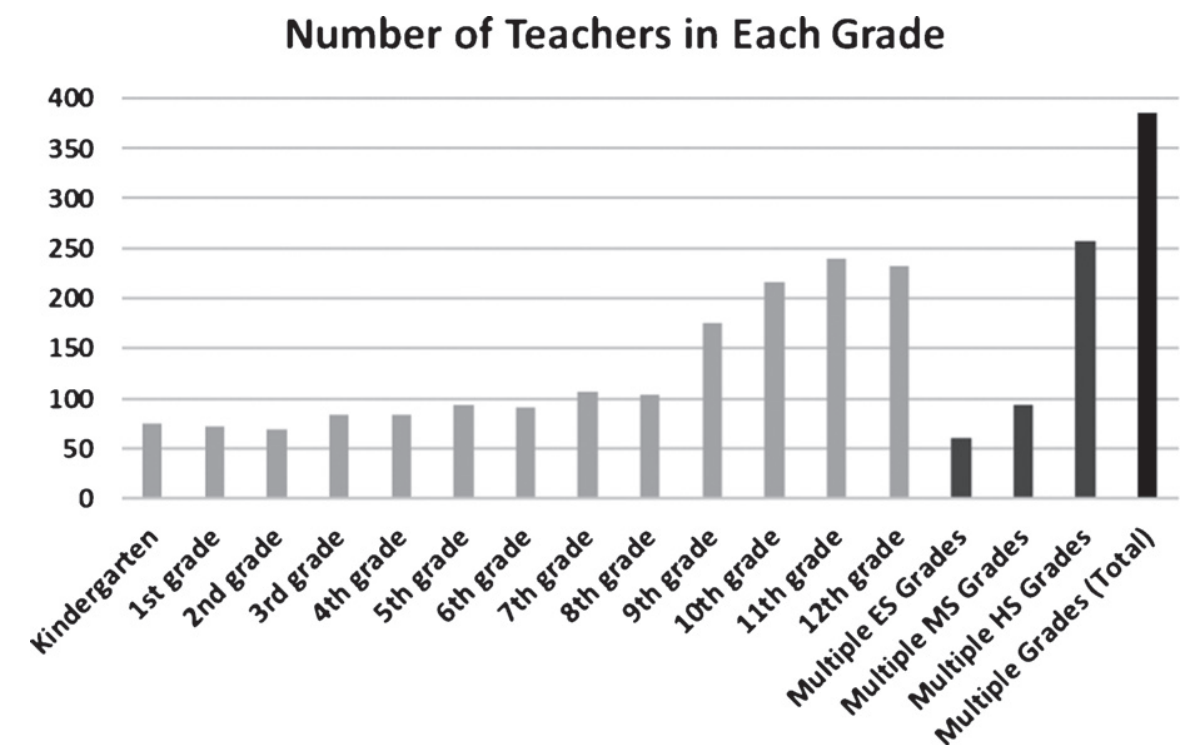

Fig. 1. Number of teachers completing the survey in each of the grades with multiple grades representing teachers who teach across grade levels. ES: Elementary, MS: Middle school, HS: High school, Total: Number across all schools. 
Table 2

Components of the survey administered by online survey to the teachers in the Greater Cincinnati area

Variable
Demographics
Age
Grade taught
Gender
Race and ethnicity
Marital status
Education
Years teaching overall
Years teaching at current school system
Number of kids
At home
Remote
Requiring assistance
Work-family balance
My work keeps me from my family activities more than I would like
The time I must devote to my job keeps me from participating equally in
household responsibilities and activities
I have to miss family activities due to the amount of time I must spend
on my work responsibilities
When I finish work I am often too frazzled to participate in family
activities/responsibilities
Tension and anxiety from my family life often weakens my ability to do
my job
Current impact of COVID-19
Quality of teaching
Patience with others
Time to complete tasks
Ability to multitask
Ability to focus
Physical health
Mental health
Ability to separate work and family
During COVID-19
I have been able to maintain a satisfactory work/family balance
How often have you felt nervous and 'stressed'?
How often have you found that you could not cope with all the things
that you had to do?
How often have you been able to control irritations in your life?
How often have you felt that you were on top of things?
Time to complete (pre- and during COVID)
Prep for class
Teach class
Grade for class

Pre- and during COVID perceptions

Stress

Management of stress

Burnout

Ability to maintain family-work balance

Pre- and during COVID perceptions of the percentage of time spent on

Web conferences Responses

Number in years

Kindergarten, $1^{\text {st }}, 2^{\text {nd }}, 3^{\text {rd }}, 4^{\text {th }}, 5^{\text {th }}, 6^{\text {th }}, 7^{\text {th }}, 8^{\text {th }}, 9^{\text {th }}, 10^{\text {th }}, 11^{\text {th }}, 12^{\text {th }}$

Male, Female, Other

Native American, Black, White, Asian, Hispanic, Hawaiian

Single, Married, Single or separated, Widowed

$\mathrm{BS}, \mathrm{MS}, \mathrm{PhD}, \mathrm{EdD}$, Special certificate, Other

Number of years

Number of years

Number and percentage

Less than preschool, Preschool, Elementary school, Middle school, High school, College

Strongly agree: 5

Moderately agree: 4

Slightly agree: 3

Slightly disagree: 2

Moderately disagree: 1

Strongly disagree: 0

Increased significantly: 6
Increased somewhat: 5
Increased slightly: 4
No change: 3
Decreased slightly: 2
Decreased somewhat: 1
Decreased significantly: 0

Never: 0

Almost never: 1

Sometimes: 2

Fairly often: 3

Very often: 4

1: less than 10 hours

2: 11 to 20 hours

3: 21 to 30 hours

4: 31 to 40 hours

5: more than 40 hours

Extremely stressed: 4 , Very stressed: 3 , Somewhat stressed: 2, Slightly stressed: 1 , Not at all stressed: 0

Extremely well: 4, Very well: 3 , Somewhat well: 2 , Slightly well: 1 , Not very well: 0

Extremely burned out: 4, Very burned out: 3 , Somewhat burned out: 2 , Slightly burned out: 1 , Not at all burned out: 0

Strongly agree: 5 , Moderately agree: 4 , Slightly agree: 3 , Slightly disagree: 2 , Moderately disagree: 1 , Strongly disagree: 0

0 : None

1: 1 to $10 \%$

2: 11 to $20 \%$

3: 21 to $30 \%$

4: 31 to $40 \%$

5: 41 to $50 \%$

6: 51 to $60 \%$

7: 61 to $70 \%$

8: 71 to $90 \%$

9: 81 to $90 \%$

10: 91 to $100 \%$

Number per week 


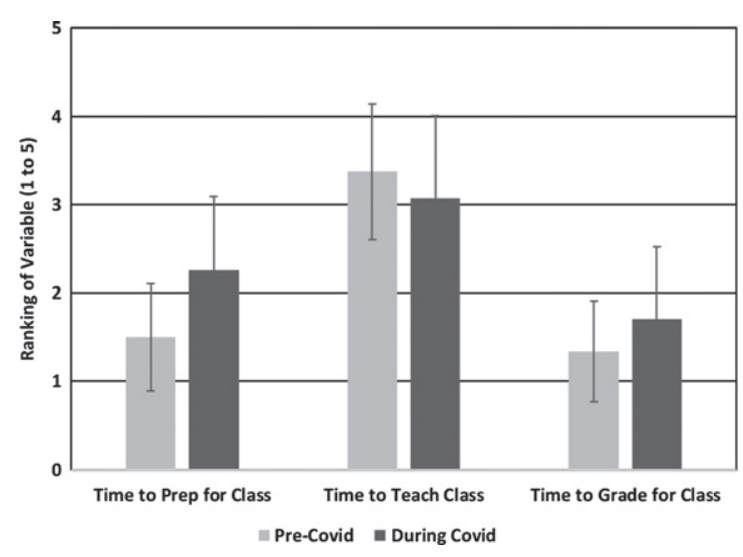

Fig. 2. Pre- and during COVID perceptions of Time to prep for class, Time to teach class, and Time to grade for class (1: less than 10 hours, $2: 11$ to 20 hours, $3: 21$ to 30 hours, $4: 31$ to 40 hours, 5 : more than 40 hours). All differences between pre and during are significant at $p<0.05$.

survey took questions from three well-established surveys inquiring about stress, burnout, and familywork balance [30-33].

\subsection{Data analyses}

Descriptive statistics were determined for each outcome variable, including averages, frequencies, and percentages. Analysis of variance (ANOVA) procedures using the SAS statistical package (Carey, NC) were used to identify whether significant differences existed between pre- and during-COVID-19 measures as well as a function of grade level (interaction between pre/post and grade level).

\section{Results}

COVID-19 had significant impact on the teaching practices where virtual meetings were non-existent (1-10\% of time and less than 1-2 times per week) prior to COVID-19 and increased to be widely used (51-60\% of the time and more than 8.5 times per week) (Fig. 2). The perception of time to complete prepping for class, teaching class, and grading for class were significantly different $(p<0.0001)$ for preCOVID and during-COVID-19 (Fig. 3). Time to prep for class was greater during-COVID-19 (above 11 to 20 hours on average) than pre-COVID-19 (below 11 to 20 hours on average). A similar trend was found for grading (pre $<$ during) but an opposite trend was found for time teaching (pre $>$ during).

COVID-19 appeared to have a significant impact on the stress and burnout levels of teachers as well

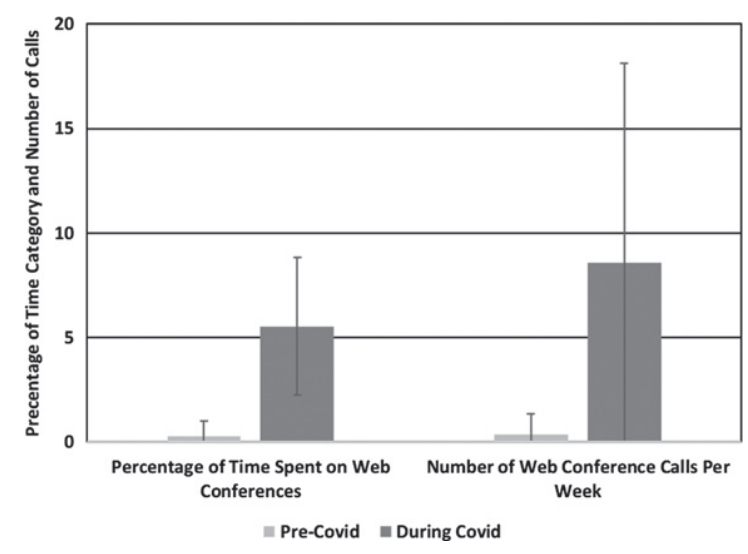

Fig. 3. Pre- and during COVID perceptions of the percentage of time spent on web conferences (0: None, 1: 1 to $10 \%, 2: 11$ to $20 \%$, 3: 21 to $30 \%, 4: 31$ to $40 \%, 5: 41$ to $50 \%, 6: 51$ to $60 \%, 7: 61$ to $70 \%, 8: 71$ to $90 \%, 9: 81$ to $90 \%, 10: 91$ to $100 \%$ ) and number of web conference calls per week. All differences between pre and during are significant at $p<0.05$.

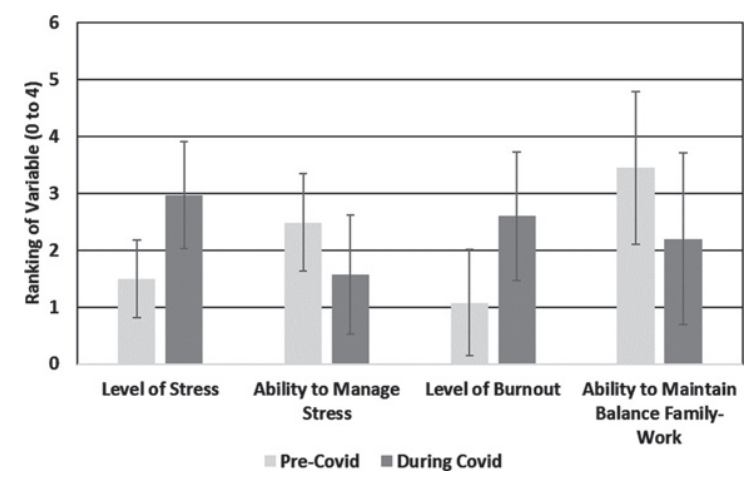

Fig. 4. Pre- and during COVID perceptions of stress (Extremely stressed: 4, Very stressed: 3, Somewhat stressed: 2, Slightly stressed: 1, Not at all stressed: 0), Management of stress (Extremely well: 4, Very well: 3 , Somewhat well: 2 , Slightly well: 1 , Not very well: 0), Burnout (Extremely burned out: 4, Very burned out: 3, Somewhat burned out: 2, Slightly burned out: 1, Not at all burned out: 0 ), Ability to maintain family-work balance (Strongly agree: 5 , Moderately agree: 4 , Slightly agree: 3 , Slightly disagree: 2 , Moderately disagree: 1 , Strongly disagree: 0 ). All differences between pre and during are significant at $p<0.05$.

(Fig. 4). On average, the stress and burnout levels significantly $(p<0.0001)$ increased during-COVID19 where stress was rated slightly to somewhat stressed pre-COVID-19 and very stressed duringCOVID-19 while burnout was rated slightly burned out pre-COVID-19 and somewhat to very burned out during-COVID-19. Teachers were also less able to manage stress and maintain a good work-family balance during-COVID-19 as compared to preCOVID-19 levels (See Fig. 4). None of the outcome 
Table 3

Impact of COVID-19 on teachers' well-being

\section{Work-family balance}

(Strongly agree: 5 , Moderately agree: 4 , Slightly agree: 3 , Slightly disagree: 2 , Moderately disagree: 1 , Strongly disagree: 0 ) \begin{tabular}{ll}
\hline My work keeps me from my family activities more than I would like (slightly agree) & $3.1(1.5)$ \\
The time I must devote to my job keeps me from participating equally in household responsibilities and activities (slightly agree) & $2.9(1.6)$ \\
I have to miss family activities due to the amount of time I must spend on my work responsibilities (slightly disagree) & $2.2(1.5)$ \\
When I finish work I am often too frazzled to participate in family activities/responsibilities (slightly agree) & $2.9(1.6)$ \\
Tension and anxiety from my family life often weakens my ability to do my job (slightly disagree) & $1.7(1.5)$
\end{tabular}

Current impact of COVID-19

(Increased significantly: 6, Increased somewhat: 5, Increased slightly: 4, No change: 3, Decreased slightly: 2, Decreased somewhat: 1, Decreased significantly: 0)

Quality of teaching (decreased slightly)

Patience with others (decreased slightly)

Time to complete tasks (no change)

During COVID-19

(Never: 0, Almost never: 1, Sometimes: 2, Fairly often: 3, Very often: 4)

I have been able to maintain a satisfactory work/family balance (sometimes)

How often have you found that you could not cope with all the things that you had to do? (sometimes)

Table 4

Number and percentage of own kids at home for the teachers

\begin{tabular}{lcccccc}
\hline & Less than preschool & Preschool & Elementary school & Middle school & High school & College \\
\hline 0 & $622(88.5 \%)$ & $635(90.3 \%)$ & $568(80.8 \%)$ & $557(79.3 \%)$ & $544(77.4 \%)$ & $553(78.7 \%)$ \\
1 & $61(8.7 \%)$ & $59(8.4 \%)$ & $104(14.8 \%)$ & $117(16.6 \%)$ & $110(15.6 \%)$ & $90(12.8 \%)$ \\
2 & $17(2.4 \%)$ & $9(1.3 \%)$ & $25(3.6 \%)$ & $28(4.0 \%)$ & $44(6.3 \%)$ & $52(7.4 \%)$ \\
3 & $3(0.4 \%)$ & $0(0.0 \%)$ & $6(0.9 \%)$ & $1(0.1 \%)$ & $4(0.6 \%)$ & $8(1.1 \%)$ \\
4 & $0(0.0 \%)$ & $0(0.0 \%)$ & $0(0.0 \%)$ & $0(0.0 \%)$ & $1(0.1 \%)$ & $0(0.0 \%)$ \\
Remote & $1(1.2 \%)$ & $7(10.3 \%)$ & $50(37.0 \%)$ & $41(28.1 \%)$ & $61(38.4 \%)$ & $118(78.7 \%)$ \\
Required assistance & $5(6.2 \%)$ & $31(48.6 \%)$ & $127(49.1 \%)$ & $116(79.5 \%)$ & $112(70.4 \%)$ & $32(21.3 \%)$ \\
\hline
\end{tabular}

variables was found to be significantly $(p>0.05)$ impacted by the level of school (e.g., elementary, middle, high school) indicating the grade level taught by the teacher had no significant impact on their stress, burnout, or work-family balance.

During COVID-19, teachers rated the ability to meet a good work-family balance to be difficult (Table 3) with all factors rated to be slightly impacted (e.g., work keeps teacher from family, teacher is more frazzled). The perceptions of the teachers also indicated that conditions during COVID-19 adversely impacted teaching quality, patience with others, ability to focus, physical and mental health, and ability to separate work and family (See Table 3). In other words, teachers were less able to balance work and family, manage stress, and stay on top of things.
The impact of COVID-19 may have been magnified for teachers with children at home (see Table 4). About $63 \%$ of the teachers reported having at least one child at home, with an average of 1.4 kids per teacher (total of 961 kids including 256 with no children, 106 with 1 child, 213 with 2 children, 97 with 3 children and 31 with 4 or more children). The percentage of teachers who had children at home learning remotely ranged from $1 \%$ to $78 \%$ depending on the children's age group, and the percentage of teachers with kids needing assistance ranged from $6 \%$ to $80 \%$.

\section{Discussion}

Teachers appear to be adversely impacted by COVID-19 and continue to be so 12 to 14 months 
into the pandemic. Technology played a huge role in the teaching effort where teachers went from almost no online meetings to teaching almost 9 times online per week. The perceived time dedicated to prepping classes and grading increased while time to teach decreased. This perception seemed to directly impact the mental and physical state of the teachers. Stress and burnout continue to be high for teachers with $72 \%$ of teachers feeling very or extremely stressed and $57 \%$ feel very or extremely burned out. These are alarming levels and appear to be higher than other studies [19, 20, 22, 23, 25-27]. Burnout leads to turnover, which has more than doubled for teachers during the COVID-19 pandemic [28]. While the COVID-19 pandemic is starting to wane, and schools are returning to in person teaching, teachers still encounter ever changing health guidelines and policies contributing to stress and burnout feelings which may manifest in adverse health outcomes and future turnover. School systems will need to address these issues and develop interventions for teachers to help them cope, whether this is for the COVID-19 pandemic or a future pandemic.

Several researchers have conducted research into interventions for stress and burnout for teachers. Traditional cognitive-behavioral approaches focus on specific, manual-based treatment protocols [34] and are feasible for workplace wellness programs as they promote general health and well-being for employees [35]. More recently, researchers have found that mindfulness meditation is an effective tool as it reduces the negative effects of stress that lead to burnout [36]. Because mindfulness targets symptoms associated with stress but may not have the stigma associated with help-seeking for mental health, mindfulness is proving to be an effective stress recovery tool for teachers [29, 30, 37]. However, school systems need to go beyond individual-level interventions to also develop organizational and individual-organizational interface (IOI) interventions that reduce the sources of teacher stress. IOI interventions often involve collaborative problem-solving and educator capacity building activities that help workers to meet or change work demands [38] whereas organizational interventions have been designed primarily to improve or support professional practice, support job redesign, and/or improve workplace support and climate [39].

The stress and demands during COVID-19 appeared to have significant impact on the family life of the teachers. Many teachers struggled to have a satisfactory work-family balance (37\% never or almost never; $20 \%$ only has sometimes). Many of the teachers not only had to deal with online courses with their students, but also with their own children. At the time of the survey in spring 2021, 29\% of the teachers had kids at home who were learning remotely and $41 \%$ who required assistance. The bottom line is that teachers have many demands on them both in school and at home, which appeared to be exacerbated by COVID-19.

One of the interesting results was the lack of significant difference between grades or even school level (elementary, middle, and high school) for the various stress, burnout, and family-work balance outcomes. The lack of significance was somewhat surprising in that our expectation was that online teaching would place different demands on the teachers at different grade levels. The results could be an indicator that although the stressors may have varied across the grade levels, the resulting stress and burnout from the stressors were the same. For example, it is more difficult to keep young students' attention than older students' attention. The results indicate the stress and burnout on the teachers appear to be more uniform than previously thought.

While many of the results are interesting, there are several points that need to be taken into consideration when interpreting the results. First, the survey was completed by a small portion of the teachers solicited (13\%), which means it is a sample of convenience. While the study population was robust with respect to ages, grade levels and resulted from diverse school selection, there is no way to know who completed the survey (it was anonymous) and by which school districts respondents were employed. The survey was sent out to a wide variety of teachers at private and public schools of varying sizes across the Greater Cincinnati area. Second, the survey asked about the perceptions of the teachers regarding preCOVID circumstances (retrospective). Retrospective perceptions have the potential for recall bias [40]. Third, timing of the study was late into the COVID-19 pandemic, which may have affected the assessments of stress and burnout. The results would mostly represent the cumulative effects of the COVID-19 pandemic. Alternatively, the assessments of stress and burnout are current levels and may be lower, as some teachers may have adapted to the new normal, where higher levels might have been present earlier in the pandemic as teachers adjusted to online or hybrid teaching. 


\section{Conclusion}

While the results of the study relied on the perceptions of the teachers, which need to be objectively verified, there are some indications that teaching is one occupation that has been impacted by COVID19 and the necessity to teach online. Even as we are emerging from the pandemic and getting back to normal, teachers are still struggling from stress and lack of family-work balance. As a result, teachers are potentially suffering from elevated burnout that may lead to high turnover rates in the near future. School systems must start to deal with mental and physical health of teachers before a large portion of them leave the profession.

\section{Conflict of interest}

The authors have no potential conflicts of interest to disclose.

\section{Funding}

This work was partially supported by the National Institute for Occupational Safety and Health through the Intergovernmental Personnel Act (IPA) Agreement. Partial support was also provided by the CCTST at the University of Cincinnati, which is funded by the National Institutes of Health (NIH) Clinical and Translational Science Award (CTSA) program, grant 2UL1TR001425-05A1.

\section{References}

[1] Darling-Hammond L. The challenge of staffing our schools. Educational Leadership. 2001;58(8):12-7.

[2] Macdonald D. The role of proletarianization in physical education teacher attrition. Research Quarterly for Exercise and Sport. 1995;66(2):129-41.

[3] Wilhelm K, Dewhurst-Savellis J, Parker G. Teacher stress? An analysis of why teachers leave and why they stay. Teachers and Teaching. 2000;6(3):291-304.

[4] Johnson S, Cooper C, Cartwright S, Donald I, Taylor P, Millet C. The experience of work-related stress across occupations. Journal of Managerial Psychology. 2005.

[5] Kyriacou C. Teacher stress: Directions for future research. Educational Review. 2001;53(1):27-35.

[6] Demerouti E, Bakker AB, Nachreiner F, Schaufeli WB. The job demands-resources model of burnout. Journal of Applied Psychology. 2001;86(3):499.

[7] Brown S, Nagel L. Preparing future teachers to respond to stress: Sources and solutions. Action in Teacher Education. 2004;26(1):34-42.
[8] Kyriacou C. Teacher stress and burnout: An international review. Educational Research. 1987;29(2):146-52.

[9] Mercer S, Gregersen T. Teacher wellbeing. Oxford University Press, 2020.

[10] Troman G. Teacher stress in the low-trust society. British Journal of Sociology in Education. 2000;21(3):331-61.

[11] Trendall C. Stress in teaching and teacher effectiveness: A study of teachers across main stream and special education. Educational Research. 31(1):52-8.

[12] Geving, AM. Identifying the types of student and teacher behaviours associated with teacher stress. Teaching and Teacher Education. 2007;23:624-40.

[13] The World Bank. World Bank Educaiton and COVID-19. 2020. Retrieved from https://www.worldbank.org/en/data/ interactive/2020/03/24/world-bank-education-and-covid19 Accessed 6/15/21.

[14] UNESCO. COVID-19 Educational Disruption and Response. 2020. Retrieved from https://en.unesco.org/covid19/ educationresponse Accessed 6/15/21.

[15] Martinez-Monteagudo MC, Ingles CJ, Granados L, Aparisi D, Garcia-Fernandez JM. Trait emotional intelligence profiles, burnout, anxiety, depression, and stress in secondary education teachers. Personality and Individual Differences. 2019;142:53-61.

[16] McQuiggan CA. Faculty development for online teaching as a catalyst for change. Journal of Asynchronous Learning Networks. 2012;16(2):27-61.

[17] Carrillo C, Flores MA. COVID-19 and teacher education: a literature review of online teaching and learning practices. European Journal of Teacher Education. 2020;43(4):46687.

[18] Kim LE, Asbury K. "Like a rug had been pulled from under you": The impact of COVID-19 on teachers in England during the first six week of the UK lockdown. British Journal of Educational Psychology. 2020;90:1062-83.

[19] Carreon T, Rotas E, Cahapay M, Garcia K, Amador R, Anoba JL. Fear of COVID-19 and Remote Teaching Burnout of Filipino K to 12 Teachers. International Journal of Educational Research and Innovation. 2021;4(15): 552-67.

[20] de Oliveira Silva DF, Cobucci RN, Lima SC, de Andrade FB. Prevalence of anxiety, depression, and stress among teachers during the COVID-19 pandemic: Systematic review. medRxiv. 2021.

[21] Alves R, Lopes T, Precioso J. Teachers' well-being in times of Covid-19 pandemic: factors that explain professional well-being. International Journal of Educational Research and Innovation. 2021;(15):203-17.

[22] Chitra A. Study on Impact of Occupational Stress on Job Satisfaction of Teachers during Covid-19 Pandemic Period. Global Development Review. 2020;4(2):52-62.

[23] Kumawat K. Perceived stress and burnout in online teaching in teachers in India during pandemic COVID-19. Indian Journal of Health Wellbeing. 2020;1:11.

[24] Ma K, Chutiyami M, Zhang Y, Nicoll S. Online teaching self-efficacy during COVID-19: Changes, its associated factors and moderators. Education and Information Technologies. 2021;10:1-23.

[25] Prasojo LD, Habibi A, Yaakob MF, Pratama R, Yusof MR, Mukminin A, Hanum F. Teachers' burnout: A SEM analysis in an Asian context. Heliyon. 2020;6(1):e03144.

[26] Sokal L, Trudel LE, Babb J. Canadian teachers' attitudes toward change, efficacy, and burnout during the COVID-19 pandemic. International Journal of Educational Research Open. 2020;1(1):100016. 
[27] Zadok-Gurman T, Jakobovich R, Dvash E, Zafrani K, Rolnik B, Ganz AB, Lev-Ari S. Effect of Inquiry-Based Stress Reduction (IBSR) Intervention on Well-Being, Resilience and Burnout of Teachers during the COVID-19 Pandemic. International Journal of Environmental Research and Public Health. 2021;18(7):3689.

[28] Pressley T. Factors Contributing to Teacher Burnout During COVID-19. Educational Researcher. 2021;16.

[29] Zadok-Gurman T, Jakobovich R, Dvash E, Zafrani K, Rolnik B, Ganz AB, Lev-Ari S. Effect of Inquiry-Based Stress Reduction (IBSR) Intervention on Well-Being, Resilience and Burnout of Teachers during the COVID-19 Pandemic. International Journal of Environmental Research and Public Health. 2021;18(7):3689.

[30] Matiz A, Fabbro F, Paschetto A, Cantone D, Paolone AR, Crescentini C. Positive impact of mindfulness meditation on mental health of female teachers during the COVID-19 outbreak in Italy. International Journal of Environmental Research and Public Health. 2020;17(18):6450.

[31] Carlson DS, Kacmar KM, Williams LJ. Construction and initial validation of a multidimensional measure of work-family conflict. Journal of Vocational Behavior. 2000;56(2):249-76.

[32] Cohen S, Kamarck T, Mermelstein R. Perceived stress scale. Measuring Stress: A Guide for Health and Social Scientists. 1994;10:1-2.

[33] Demerouti E, Bakker AB. The Oldenburg Burnout Inventory: A good alternative to measure burnout and engagement. Handbook of Stress and Burnout in Health Care. 2008;65-78.
[34] Hayes SC. Acceptance and commitment therapy, relational frame theory, and the third wave of behavioral and cognitive therapies. Behavior Therapy. 2004;35(4):639-65.

[35] Riley KE, Park CL, Wilson A, Sabo AN, Antoni MH, Braun TD, Cope S. Improving physical and mental health in frontline mental health care providers: Yoga-based stress management versus cognitive behavioral stress management. Journal of Workplace Behavioral Health. 2017;12(1): 26-48.

[36] von der Embse N, Ryan SV, Gibbs T, Mankin A. Teacher stress interventions: A systematic review. Psychology in the Schools. 2019;56(8):1328-43.

[37] Flook L, Goldberg SB, Pinger L, Bonus K, Davidson RJ. Mindfulness for teachers: A pilot study to assess effects of stress, burnout, and teaching efficacy. Mind, Brain, and Education. 2013;7(3):182-95.

[38] Randall R, Travers C. Individual-organizational interface (IOI) interventions to address educator stress. In McIntyre TM, McIntyre SE, Francis DJ (Eds.), Educator Stress: An Occupational Health Perspective, Springer. 2017;347-68.

[39] Landsbergis P, Zoeckler J, Rivera B, Alexander D, Bahruth A, Hord W. Organizational interventions to reduce sources of K-12 teachers' occupational stress. In T. M. McIntyre, S. E. McIntyre, \& D. J. Francis (Eds.), Educator Stress: An Occupational Health Perspective, Springer. 2017;369-410.

[40] Coughlin SS. Recall bias in epidemiologic studies. Journal of Clinical Epidemiology. 1990;43(1):87-91. 